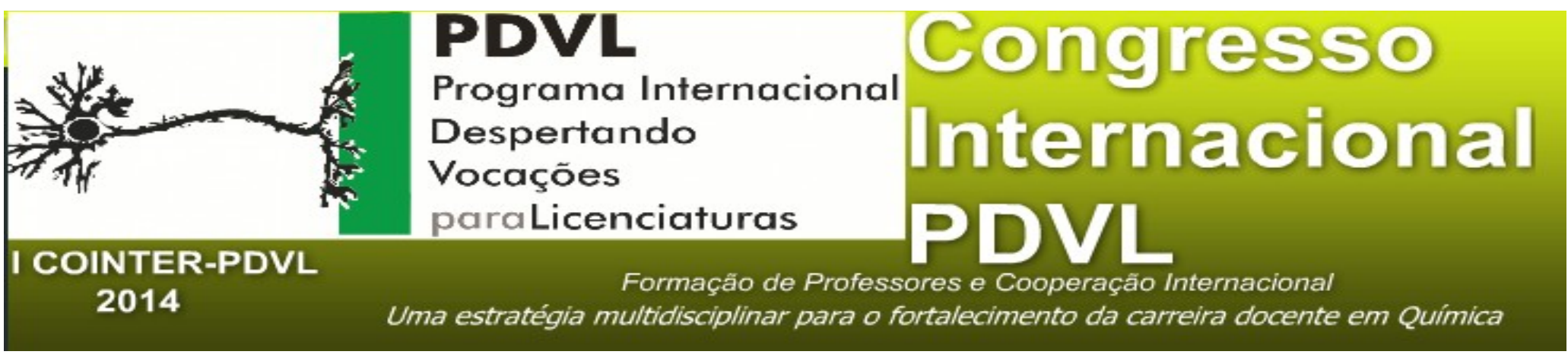

\title{
A IMPORTÂNCIA DO PIBID PARA UM ALUNO DO CIÊNCIAS SEM FRONTEIRAS COMO PROFESSOR ASSISTENTE EM UMA TURMA DE QUÍMICA NOS ESTADOS UNIDOS DA AMÉRICA
}

\author{
Apresentação: Comunicação Oral \\ Walker de Lima Cordeiroํㅜ Maria Ismênia Gomes Nunes²; Edmar Marinho³; Johnnatan \\ Duarte de Freitas ${ }^{4}$
}

\begin{abstract}
Resumo
Este trabalho foi elaborado por alunos do Instituto Federal de Alagoas, a partir de suas experiências ao longo de dois anos no Programa Institucional de Bolsas de Iniciação a Docência - PIBID. Porém, após a seleção de um aluno da equipe do PIBID para fazer parte do programa Ciências sem Fronteiras, um programa do Governo Federal que permite os estudantes brasileiros um período de estudos no exterior, os integrantes da equipe decidiram aplicar com os alunos de uma instituição dos Estados Unidos da América as ideias aplicadas no Brasil. Em uma turma de ensino médio na Gateway Community College no Estado do Arizona, as metodologias desenvolvidas no PIBID foram compartilhadas com os alunos Americanos. O aluno brasileiro em questão, foi selecionado para participar como professor assistente em Química em uma turma da instituição Americana. Com aulas e métodos antes aplicados no Brasil, o aluno pode verificar que as diferenças entre o sistema educacional Brasileiro e Americano apresentaram significativos resultados na aceitação das metodologias em questão. Com a experiência em uma instituição Internacional foi possível verificar que a formação de professores no Brasil tem sim alguns pontos a serem aperfeiçoados, todavia, foi extremamente perceptível que a inserção em um programa que permite o contato com a docência durante a formação, foi um diferencial do aluno brasileiro em sua experiência como professor assistente nos Estados Unidos da América. Ratificando que, as medidas realizadas com o intuito na melhoria da formação do professor, como por exemplo a criação do PIBID, será com certeza, um
\end{abstract}

1 Licenciando em Química/IFAL/GPAES/wallker_lima@hotmail.com

2 Licenciando em Química / IFAL /PIBID/ ismenianunes@hotmail.com

3 Licenciando em Química / IFAL /PIBID / quiedmar@hotmail.com

4 Doutor/IFAL/ Coordenador Local PDVL / johnnatandf@gmail.com 
diferencial para os estudantes dos cursos de Licenciatura. Este programa fará com que os futuros docentes possam , após sua formação inicial, encarar com propriedade uma turma de alunos em nossas escolas brasileiras ou até em unidades de educação pelo mundo.

Palavras-Chave: PIBID, Ciências sem Fronteiras, Metodologias

\section{Introdução}

O curso de Licenciatura em Química do Instituto Federal de Alagoas foi contemplado pelo PIBID no ano de 2011, sendo o segundo ano de funcionamento do curso, após a inserção do PIBID no curso de Licenciatura em Química, várias atividades foram desenvolvidas, com o objetivo de vivenciar a prática docente e de preparar os futuros professores para o desafio que os espera, inserindo-os no ambiente escolar.

Durante todo este período os alunos foram instruídos a preparar artigos, e elaborar planos de aula, utilizando materiais de baixo custo e de fácil acesso ao aluno, com o objetivo de torna a química mais acessível aos alunos.

Os alunos também obtiveram acesso ao ambiente de sala de aula, adquirindo um primeiro contato direto com os alunos e analisando de que forma eles observam a profissão docente.

O acesso aos laboratórios de química da instituição obtendo contato com vidrarias e reagentes, sempre aos cuidados de um profissional qualificado, como também aprender como manuseá-los e armazená-los, ajudou aos alunos no preparo de experimentos químicos realizados com alunos do ensino médio

Através dos experimentos realizados, os integrantes do PIBID perceberam que a Química podia sim ser transmitida de uma forma mais simples, em alguns dos seus conteúdos.

A oportunidade de aplicar conteúdos até então um pouco complexos para muitos alunos foi uma das oportunidades dentro do projeto, depois do experimento realizado o a maioria dos assuntos se tornaram mais interessante para os alunos, como exemplo destas atividades, pode-se citar um experimento sobre o bafômetro, onde o conteúdo de Oxirredução mostrando as reações químicas existentes nestes equipamentos.

Em 2013, com a escolha de um dos participantes do PIBID, para participação do Programa Ciências sem Fronteiras, umas das primeiras indagações feitas pelo próprio aluno foi se seria possível a utilização de alguma metodologia aplicada no PIBID (Brasil) poderia ser utilizada na Instituição no exterior (EUA). O aluno fora indagado se não seria muito cedo para um planejamento futuro, e como resposta (fruto da vivência no PIBID) o aluno mostrou que:

Há os que julgam que insistir no planejamento é buscar prisões, impedir a inspiração, esquecer-se das pessoas. Isso realmente é assim quando há os que 
dominam o planejamento, os que realizam planejamento burocrático e tecnicamente. Não é assim para aqueles que usam o planejamento como uma estrada asfaltada para ir mais depressa a algum lugar. Pode-se dizer que o asfalto tira a liberdade porque nos constrange a ir por ele sem nos deixar o caminho dos campos e das cachoeiras. Mas, se temos liberdade de escolher os lugares onde precisamos ir, o asfalto É um modo de irmos melhor (GANDIN, 2007, P.110)

O planejamento foi essencial para que ao chegar na instituição americana, as atividades as quais foram desenvolvidas no Brasil fossem repensadas para uma realidade de uma instituição no Exterior, até por que o ato de planejar é "atividade intrínseca à educação por suas características básicas de evitar o improviso, prever o futuro, e estabelecer caminhos que podem nortear mais apropriadamente a execução da ação educativa " (PADILHA, 2003, P.45).

Ao chegar nos Estados Unidos da América e ser selecionado para ser professor assistente em Química, umas dos questionamentos feito pelo professor titular da disciplina ao aluno brasileiro foi de como seria a metodologia usada com os alunos de química de uma turma de ensino médio nos Estados Unidos. Ao expor algumas ideias de utilização de materiais alternativos para o aprendizado de química, tentando fazer com que o aluno pudesse se sentir mais familiarizado com a química. O professor ficou bastante entusiasmado com a forma como fora sugerido pelo aluno brasileiro. E ressaltou que a forma como seriam compartilhados os conteúdos de química com os alunos, seriam determinante para o aprendizado dos alunos em sala de aula. Desta forma, pode-se verificar as diversas óticas sobre o processo de ensino - aprendizagem, bem como avaliar as práticas pedagógicas utilizadas no ensino, pode mudar o entendimento do aluno de química, como afirma KUENZER (2009, p. 153) “[...] acreditamos que uma seleção planejada e cuidadosa dos assuntos a serem tratados, associada a uma metodologia adequada, pode mudar positivamente o perfil da área de Química.”. 


\section{Fundamentação Teórica}

Além das atividades desenvolvidas, o PIBID vem contribuindo para formação dos bolsistas, de forma reflexiva, repensando sobre as metodologias pedagógicas, aproximando os futuros docentes com o âmbito escolar, conscientizando-os da importância do respeito mútuo e de suas individualidades, tornando-os profissionais preparados para atuar de forma eficaz, como destaca GARCIA (1995, p.161):

[...] o professor pode saber que o aprendizado, isto é, a educação só é viável com o respeito da individualidade do educando, ou do grupo, e com o consenso e a cooperação activa deles, intelectual e afectivamente empenhados.

No intuito de uma atuação com novas abordagens de ensino - aprendizagem, o PIBID tem estimulado os futuros docentes a uma importante reflexão sobre a realidade escolar, despertando no licenciando o anseio por educar, entendendo que a educação deve contribuir para a construção do conhecimento e formação humana dos discentes. Tais conceitos foram muito abordados pelo professor titular da disciplina de química na instituição Americana, e até pelos próprios alunos que chegaram a questionar se todos os professores no Brasil agiam daquela mesma forma ou se somente os alunos que conseguiam estudar no exterior possuíam tais qualidades.

No PIBID, a partir desta problemática, é possível fazer uma reflexão sobre o ensino da química, com o propósito de formar professores que atuem de forma comprometida em sala de aula, o que permitiria uma melhor compreensão sobre a química e, despertaria um maior interesse sobre a disciplina, desmificando assim a não aprendizagem da mesma, conforme vislumbra GADOTTI (2000, p.63):

[...] o ser educador não nasce ontologicamente com a pessoa nem depende de um despertar mágico ou de uma iluminação súbita da consciência para um compromisso até então ausente de um projeto de vida. 


\section{Metodologia}

O procedimento utilizado foi o da Observação participante. Para Mann (1970:96) a observação participante é uma "tentativa de colocar o observador e o observado do mesmo lado, tornando-se o observador um membro do grupo de modo a vivenciar o que eles vivenciam e trabalhar dentro do sistema de referência deles". O campo de estudo foi uma turma do ensino médio da Gateway Community College no estado do Arizona nos Estados Unidos da América.

A partir de assuntos de química pré determinado pelo professor titular da disciplina, alguns experimentos foram elaborados para que, de forma bem simples, fossem repassados aos alunos, tentando aproximar ao máximo a realidade dos alunos como a química. Dentre os vários experimentos realizados em sala de aula, o que mais chamou atenção foi o experimento proposto, com o intuito de simular o teste do bafômetro (o mesmo que também chamou bastante atenção entre os alunos brasileiros) e verificar como ocorre a evidencia da presença de alcool no organismo. A partir do conceito de equilibrio Químico, fora proposto a "criação de um bafômetro". Os alunos deveriam realizar um experimento para simular o teste do bafômetro a fim de compreender sua funcionalidade e como pode-se evidenciar a presença de álcool no organismo a partir das reações realizadas neste experimento. Para realização deste experimento foram utilizados, dentre vários recursos, alguns balões de aniversário, algodão, fita para vedar, giz, além de algumas vidrarias e reagentes químicos como o Dicromato de potássio. O procedimento consistia em encher alguns balões com diferentes substâncias alcoólicas ( vinho, cerveja, whisky) pois cada uma havia uma concentração de álcool diferente. O balão era conectado em uma pequena mangueira e dentro da mangueira existia alguns pedaços de giz molhado no dicromato de potássio. A coloração do dicromato de potássio quando o balão era esvaziado dependia da concentração de álcool na bebida utilizada.

\section{Resultados e Discussões}

Os alunos ficaram encantado como a química podia se explicado de forma tão simples. Alguns alunos pediram autorização para fazer o experimento em casa e mostrar aos seus pais ( nos Estados Unidos, o manuseio de substâncias químicas por pessoas não autorizada é realmente criterioso), por este motivo, o professor não os autorizou e eles pediram pra realizar este experimento em outra oportunidade na presença dos seus familiares. 
Em todo o momento os alunos questionavam se as aulas no Brasil eram desta forma, e por qual motivo os brasileiros não gostavam de química, já que a química era ensinada de uma forma tão simples e divertida.

Nos Estados Unidos da América, juntamente com os alunos de química do ensino médio da Gateway Community College, as atividades propostas tiveram um caráter "Pibidiano", o que quer dizer, que as propostas levadas para os alunos, foram essencialmente as mesmas desenvolvidas no Brasil, e o que chamou mais atenção em uma dessas abordagens em sala de aula nos Estados Unidos foi que na Gateway Community College os alunos da turma em questão não perguntavam frequentemente (ao professor titular) quando eles tinham algum tipo de dúvida. No entanto, depois de algumas aulas utilizando metodologias aplicadas no PIBID ( Brasil) , um estudante perguntou algo sobre a Lei de Boyle, lhe foi respondido de uma maneira bem simples (como nos experimentos realizados em sala de aula). Depois de alguns minutos explicando, o aluno respondeu: " parece até que agora eu sei tudo de química, acho que não percebia o quanto a química estava tão perto de mim, se eu tivesse aulas assim, eu já teria aprendido tudo".

Tendo em vista a dificuldade na formação de professores em todo país, fato que ressalta as deficiências existentes na educação do país, principalmente no Estado de Alagoas. Este projeto tem por finalidade contribuir na formação dos novos professores, numa perspectiva de conhecer as diversas óticas do processo educativo, a fim de repensar em novas metodologias de ensino.

Através de suas atividades, o PIBID vem contribuindo para que os futuros professores de química entendam que a construção do conhecimento se dá de várias formas, ressaltando, por exemplo, a valorização do próximo e as diferenças entre os indivíduos, através de atividades realizadas em equipe.

Enfatiza DELORS (2004, p.97),

A educação tem por missão, por um lado, transmitir conhecimentos sobre a diversidade da espécie humana e, por outro lado, levar as pessoas a tomar consciência das semelhanças e da interdependência entre todos os seres humanos do planeta.

Apesar de algumas dificuldades no idioma, visto que o intercâmbio tinha como uma das finalidades a inserção do aluno brasileiro na cultura e no idioma, os experimentos realizados em sala de aula fez com a distância "natural" devido a complexidade do idioma diminuísse a cada aula. A simplicidade de alguns experimentos fizeram com que os alunos americanos percebessem que eles podiam entender a química de uma maneira muito simples e prática. A química realmente aproximou os alunos americanos com o aluno brasileiro. 


\section{Conclusões}

Em vista que o PIBID objetiva contribuir com a formação dos futuros professores, numa perspectiva de iniciação à docência, o mesmo vem dando subsídios necessários para uma formação crítica e reflexiva sobre a atuação da profissão a fim de estimular novas metodologias de ensino-aprendizagem.

Várias atividades contribuíram para que isso ocorresse, dentre as quais o contato direto com os alunos e professores do ensino médio, proporcionando uma vivência no processo educativo.

Além disso, o PIBID propõe aos futuros professores uma nova visão sobre a escola, preparando-os para se adaptar, recriar e se transformar diante das mudanças sócio-econômicapolitica-cultural impostas pela e na sociedade no decorrer do tempo.

Por fim, reconhecemos que este projeto nos aproxima da realidade do âmbito escolar, lócus da atuação do professor, tendo em vista que o mesmo nos permite o contato com alunos, professores e demais profissionais da escola, possibilitando uma visão sobre diversas óticas do processo ensino aprendizagem.

Foi extremamente perceptível que a inserção em um programa que permite o contato com a docência durante a formação dos futuros professores, contribui para a desenvoltura do aluno brasileiro no exterior, sendo um diferencial em sua experiência como professor assistente nos Estados Unidos da América. Os professores americanos ao presenciar as aulas ministrada pelo aluno brasileiro, o questionaram quantos anos de experiência na docência o aluno brasileiro possuía. Ao ser explicado que no Brasil havia um projeto de inserção dos alunos dos cursos de Licenciatura, os professores Americanos ficaram surpresos com a alta desenvoltura demonstrada pelo brasileiro. Essas experiências em território internacional vem ratificar que, as medidas realizadas com o intuito na melhoria da formação do professor, como por exemplo a criação do PIBID, tem sido com certeza, um diferencial para os estudantes dos cursos de Licenciatura. Este programa fará com que os futuros docentes possam , após sua formação inicial, encarar com propriedade uma turma de alunos em nossas escolas brasileiras ou até em unidades de educação pelo mundo. 


\section{Referências}

DELORS, J. Educação: um tesouro a descobrir. 9 ed. São Paulo: Cortez, 2004.

FREIRE, P. Pedagogia da autonomia: saberes necessários à pratica educativa. São Paulo: Paz e Terra, 1996.

GADOTTI, M. et al. Perspectivas atuais da educação. Porto Alegre: Artes Médicas Sul, 2004

GANDIN, Danilo. Planejamento como prática educativa. 16º ed. São Paulo: Loyola 2007.

GARCIA, M. C. A formação de professores: novas perspectivas baseadas na investigação sobre o pensamento do professor. In: NÓVOA, A. Os professores e a sua formação. 2 ed. Lisboa: Nova Enciclopédia, 1995.

KUENZER, A. Ensino médio: construindo uma proposta para os que vivem do trabalho. 6 ed. São Paulo: Cortez, 2009.

MANN, Peter H. Métodos de investigação sociológica. Rio de Janeiro: Zahar, 1970

PADILHA, Paulo Roberto. Planejamento dialógico. São Paulo: Cortez 2003 